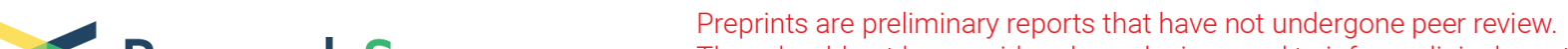 Research Square
or referenced by the media as validated information.
}

\section{The Knowledge, Attitudes and Practices of Malaria and The Risk of Malaria Infection Among Chinese Population in Sierra Leone}

Hong Tu

National Institute for Parasitic Control and Prevention,Chinese Center for Disease Control and Prevention https://orcid.org/0000-0001-8652-5171

\section{Zhao Ning}

National Institute for Communicable Disease Control and Prevention

Jun Feng

National Institute of Parasitic Diseases, Chinese Center for Diseases Control and Prevention

Jianhai Yin

National Insitute of Parasitic Diseases, Chinese Center for Diseases Control and Prevention

Zhigui Xia ( $\nabla$ xiazg@nipd.chinacdc.cn )

National Institute for Parasitic Control and Prevention,Chinese Center for Disease Control and

Prevention

\section{Zhaojun Duan}

National Institute for Viral Disease Control and Prevention

\section{Xiaohui Zou}

National Institute for Viral Disease Control and Prevention

\section{Lili Wang}

Globle Public Health Center, Chinese Center for Diseases Control and Prevention

\section{Yang Liu}

National Institute for Viral Disease Control and Prevention

\section{Jiayu Wan}

Institute of Military Veterinary, Academy of Military Medical Sciences

\section{Yingze Zhao}

National Institute for Viral Disease Control and Prevention

\section{Xiao Zheng}

National Institute for Communicable Diseases Control and Prevention

\section{Yong Sun}

Anhui Provincial Center for Disease Control and Prevention

\section{Jiangtao $\mathrm{Ma}$}

Ningxia Provincal Center for Diseases Control and Prevention

Wei Luo 


\section{Research}

Keywords: Malaria, Malaria control, Health education, Sierra Leone, Chinese

Posted Date: September 8th, 2020

DOI: https://doi.org/10.21203/rs.3.rs-69259/v1

License: (c) (1) This work is licensed under a Creative Commons Attribution 4.0 International License. Read Full License 


\section{Abstract}

Background: The risk of malaria importation from malaria hyperendemic regions has threatened the achievement of the malaria elimination goal of China. However, few studies have focused on malaria control interventions among Chinese population in Africa. The aims of this study were to assess the knowledge, attitudes and practices (KAP) of malaria and the risk of malaria infection among Chinese population in Sierra Leone, then to improve the knowledge of malaria among Chinese population in Sierra Leone through health education interventions.

Methods: Cluster random sampling method was undertaken to select the overseas Chinese from 27 Chinese institutions as respondents in Sierra Leone. Cross-sectional surveys of malaria KAP and the risk of malaria infection were performed on respondents by trained investigators. Health education training were conducted to educate respondents knowledge of malaria after the surveys. The same questionnaires of malaria KAP as before the training were used to evaluate the effect of health education interventions. Correlation analyses of results were performed by T test, ANOVA, Chi-Square and Logistics regression model.

Results: A total of 134 respondents fully completed questionnaires were analyzed before health education training with mainly engaged in (73.88\%) outdoor work. Majority of participators $(82.84 \%)$ were from 20 Chinese provinces. About half of participators (49.25\%) had not received malaria health education before going abroad. The practices of prevention malaria were used in most respondents, $84.33 \%$ (113/134) used mosquito net every day, $90.30 \%$ (121/134) were equipped with screen doors and Windows in their dwellings, $73.88 \%$ (99/134) used mosquito repellent when going out, and $74.63 \%$ (100/134) used mosquito insecticide at home. The average awareness rate of malaria knowledge of respondents without malaria training before going abroad (41.69\%) was significantly lower than that of with malaria training (53.41\%) $(T=3.337, \mathrm{P}=0.001)$. According to Logistics regression analysis, age $(\mathrm{OR}=2.6,95 \% \mathrm{Cl}(1.0,8.8))$ and male $(\mathrm{OR}=3.2,95 \% \mathrm{Cl}(1.1,9.4))$ were the main factors whether the awareness rate of malaria knowledge reaches $60 \%$ before the training. After health education training, the awareness rate of malaria knowledge of 134 respondents increased to $87.62 \%$, which was significantly higher than that of before the training (44.4\%) $(\mathrm{P}<0.05) .29 .10 \%(39 / 134)$ of all respondents had infected malaria in the past year. $37.37 \%$ (37/99) of outdoor workers were infected with malaria, which was significantly higher than $5.71 \%(6 / 35)$ of indoor workers with a significant difference $(X 2=12.561, P=0.000)$.According to Logistics regression analysis, outdoor work was the main risk factor for malaria infection $(\mathrm{OR}=6.5$, $95 \% \mathrm{Cl}(1.3,31.7))$.

Conclusion The Chinese in Sierra Leone lacked malaria knowledge training with a low awareness of malaria knowledge, and had inadequate personal prevention with high risk of malaria infection. Health education training could improve their knowledge of malaria. That implies the publicity of malaria prevention and control and outdoor prevention and control measures for overseas Chinese in Sierra Leone should be strengthened. 


\section{Introduction}

In 2018, malaria was endemic in 91 countries and regions, with most malaria cases and deaths concentrated in sub-Saharan Africa, among which Sierra Leone is one of the ten countries with the highest malaria burden [1].Sierra Leone was located in west Africa, south of the Sahara Desert, north latitude $8 \sim 11^{\circ}$ and west of the Atlantic Ocean. It has a tropical rain forest climate. Anopheles mosquitoes breed rapidly and plasmodium spreads widely. By contrast, China has not reported local malaria cases for three consecutive years since $2017[2,3]$, and malaria has been eliminated in all epidemic provinces. In recent years, with the launch of global business, the number of Chinese going to sierra leone and other African countries for international assistance, exchange, investment, business and other activities has been increasing rapidly. There are still about 3,000 imported malaria cases every year, among which Africa has become the main source of imported malaria in China[4-9]. Chinese were not generally susceptible to falciparum malaria in China, so oversee travelers infected with falciparum malaria without treatment in time easily deteriorated into severe malaria with serious complications, resulting in about 30 imported malaria deaths in China every year [10].

Recent decades a large number of Chinese people went to Africa for work. By the end of 2018, there were 997,000 Chinese labor cooperation personnel working overseas, of which about 281,000 are in Africa[11]. And 1,398 Chinese labor service workers in Sierra Leone in 2018[12]. If private business and tourism included, the estimated number of Chinese in Sierra Leone was around 3,000. From 2016 to 2019, 30-60 malaria cases imported from Sierra Leone each year in China, with no significant downward trend[8, 13]. However, most Chinese in Africa were not well educated and lack of knowledge about malaria with malaria hyperendemic environment, weak public health infrastructure and high risk of malaria infection, which have brought great challenges to China's imported malaria prevention and control [12]. Therefore, China needs to move forward the line of defense for imported malaria.

In order to understand the risk of malaria and their KAP of malaria among overseas Chinese, this study conducted KAP about malaria and malaria risk survey and performed malaria health education interventions for Chinese in Sierra Leone from September to October 2019, then evaluated the interventions'effect and provided a basis for carrying out effective interventions in a targeted way.

\section{Methods}

The respondents were randomly selected by cluster random sampling method from 21 Chinese institutions in Sierra Leone from 11 Chinese-funded institutions, covering 200 people, for investigation and cognitive intervention. The minimum sample size of 96 cases $(a=0.05,=0.1, P=0.4)$ was calculated by the formula sample formula of cross-sectional investigation. The actual number of 134 people participated in KAP survey and health education training, and the response rate was $97.8 \%$ after the training. 


$$
N=\left(\frac{Z_{1-q / 2}}{\delta}\right)^{2} \times P \times(1-P)
$$

The questionnaire of malaria KAP and malaria risk Surveys were designed by the epidemiologist expert group, which included basic information of respondents, knowledge and attitude of malaria and malaria prevention measures. The surveys were carried out by 4 investigators and supervised by 2 coordinators before health education training. The following was teaching respondents the knowledge of malaria and mosquito vector by using face to face teaching, and lecturer showed the samples of Anopheles, Culex and Aedes mosquitoes by 2 malaria experts. Simultaneously, the general situation of malaria infection in Sierra Leone, breeding habits of mosquitoes, the basic knowledge of plasmodium, and the specific measures of mosquito and malaria prevention were included the training contents. After health education training, questionnaires on malaria KAP were carried out and the training effect was evaluated by 4 investigators and 2 coordinators.

Double entry method was used for data entry by Epidata3.0 software. Version 4.0.2 of the R statistical software (R Foundation for Statistical Computing, Vienna, Austria) was used to conduct statistical analysis and plot the distribution of respondents' migration. Knowledge of malaria was calculated by the number of correct answers compared with the total number of questions, and the awareness rate of malaria knowledge reached $60 \%$ that denoted as up to standard. The results were performed as description analysis, and the difference of the awareness rate of malaria between before and after health education training were conducted by T test, ANOVA, Chi-Square. Correlation analysis were used by ChiSquare and Logistics regression model. For Logistics regression analysis, selected variables were dichotomized into two categories with presence of certain characters/conditions $=1$ and absence $=0$. The factors on the awareness rate of malaria knowledge and the risk of malaria infection with univariate analysis statistically significant were selected into Logistics regression model. $\mathrm{P}<0.05$ indicated that the difference was statistically significant.

\section{Results}

\section{Demographic profile}

A total of 134 respondents fully completed questionnaires with 113 (84.33\%) males and 21 (15.67\%) females. All respondents were lived in the capital of Sierra Leone, Freetown. The average age of respondents was 39.69 years, ranging from 22 to 58 years. The majority of respondents were $(73.88 \%)$ outdoor work, (78.36\%) business and workers, and (76.87\%) came from company and private institutes with $41.79 \%$ college education or undergraduate education and $24.63 \%$ had graduate education or above. (Table1)

\section{Respondents' migration}


82.84\% respondents were from 20 Chinese provinces, $17.16 \%$ came from Guangzhou, Xi an, Zhengzhou, Qingdao, Shanghai, Chongqing and Chengdu. 50.75\% respondents had accepted health education training related malaria before going abroad with came from 19 provinces in mainland China, and among them, $48.48 \%$ (32/66) of respondents were received health education training about malaria from sending institutions, whereas $28.79 \%$ (19/66) were customs institutions, only $16.67 \%(11 / 66)$ were Centers for Disease Control(CDC) institutions, and 6.06\% (4/66) were hospitals and other places. Among 134 respondents, most of their exit customs (82.84\%) were in Beijing, whereas others were scattered in 7 cities, including Guangzhou, Xi an, Zhengzhou, Qingdao, Shanghai, Chongqing and Chengdu (Figure 1).

\section{Practices of malaria prevention}

At least 2 measures among mosquito nets, screen doors and Windows, repellents and insecticides were used in all respondents. $84.33 \%$ of 134 respondents used mosquito net every day, $90.30 \%$ were equipped with screen doors and Windows in their dwellings, and $73.88 \%$ used repellent when going out, and $74.63 \%$ used mosquito repellent or insecticide at home.

\section{Malaria Knowledge between before and after health education training}

Before health education training, the average awareness rate of malaria knowledge of respondents without malaria control training $(40.93 \%)$ was significantly lower than that of having malaria control training (47.98\%) $(\mathrm{T}=2.333, \mathrm{P}=0.021)$. The awareness rate of malaria knowledge training of males $\triangle 42.43 \% \bigotimes$ was lower than that of females $(55.0 \%$, ) with difference significantly $(T=3.077, P=0.003)$. The awareness rate of malaria knowledge of respondents aged 45 or above $(39.74 \%)$ was lower than that of respondents aged below 45 years $(47.36 \%)(T=2.462, P=0.015)$. The awareness rate of malaria knowledge of respondents dispatched from private enterprises $(41.69 \%)$ was lower than that of dispatched government institutions $(53.41 \%)(T=3.337, P=0.001)$. The higher the degree of respondents have the higher awareness rate of malaria knowledge $(T=6.152, P=0.046)$. Whether to use mosquito nets every day and the difference type of work were no statistically significant $(P>0.05)$.According to Logistics regression analysis, age $(\mathrm{OR}=2.6,95 \% \mathrm{Cl}(1.0,8.8))$ and male $(\mathrm{OR}=3.2,95 \% \mathrm{Cl}(1.1,9.4))$ were the main factors influenced whether the awareness rate of malaria knowledge reaches $60 \%$ before health education training(Table 2 ).

After health education training, the awareness rate of malaria knowledge of 134 respondents dramatically increased to $87.62 \%$ that were significantly higher than $44.4 \%$ before training $(P<0.05)$. After the training, the awareness rate of malaria knowledge of respondents aged 45 or above was still lower than that of respondents aged below 45 years $(T=5.139, P=0.000)$; the lower awareness rate of malaria knowledge of respondents were degree below junior college or below(78.28\%), worker and businessmen $(86.33 \%)$ with statistics significantly $(P<0.05)$. (table 1$)$

\section{Risk and factors of malaria infection}


$29.10 \%$ of 134 respondents had infected malaria in the past year, which the average frequency of infected malaria was 1.46 times (1-6 times). 37.37\% (37/99) of outdoor workers were infected with malaria, which was significantly higher than $5.71 \%(6 / 35)$ of indoor workers $\left(\chi^{2}=12.561\right.$, $\mathrm{P}=0.000) .35 .37 \%(29 / 82)$ of those aged below 45 years had infected malaria in the past year, significantly higher than $19.23 \%(10 / 52)$ of those aged 45 or above $\left(\chi^{2}=4.015, P=0.045\right)$.For occupation, $35.24 \%(37 / 105)$ of workers and business had infected malaria in the past year, which was higher than $6.9 \%(2 / 29)$ of teachers, medical workers and researchers $\left(\chi^{2}=8.846, \mathrm{P}=0.003\right) .36 .89 \%(38 / 103)$ of private enterprises or individuals had infected malaria in the past year, which was higher than that of government departments and public institutions $(3.22 \%(1 / 31))\left(\chi^{2}=13.090, \mathrm{P}=0.000\right)$. However, there was no significant correlation among gender differences, whether they had received malaria knowledge training before going abroad, whether to use mosquito net every day, whether to use repellent when going out, whether to use mosquito pesticides and whether to install screen doors and Windows at home $(P<0.05)$, as shown in Table 1.

According to Logistics regression analysis, outdoor work was the main risk factor for malaria infection $(\mathrm{OR}=6.5,95 \% \mathrm{Cl}(1.3,31.7))$. Table 3 for details.

\section{Discussion}

With many years endeavor, no autochthonous malaria cases have reported since 2017 in China Mainland[9]. Nevertheless, the goal of achieving elimination malaria by 2020 in China, has been challenged by the steady stream of imported malaria cases. To prevent resurgences of indigenous cases, it is critical to implement and effective surveillance systems, to stop the transmission by detecting all possible malaria cases in a timely manner. Effective surveillance systems may be not decrease imported malaria effectively in China, and China have stable number of imported malaria cases from 2016 to 2019. This is where the important role if community involvement and the practices of the population[14]. This study is the first time to explore the situation of malaria KAP and the infection risk of malaria among Oversea Chinese in Africa, so as to provide considerations to future prevention and control measure.

Most imported malaria cases still infected in Africa and Southeast Asia, and a number of studies have shown that the awareness rate of malaria knowledge among oversea labors was low $[8,15,16]$. Finding from this study shows that the awareness rate of malaria knowledge among Chinese population in Sierra Leone was low (44.4\%), and who was male aged 45 years or above with less education had a low awareness of malaria knowledge, which was similar to other studies in China [16]. At present, most of Chinese labor workers and businessman from government institutes and large international corporation travelled to African countries would receive training on malaria prevention before going abroad, but most private companies seldom carried out health education training related malaria before going abroad [17].In Sierra Leone, most Chinese received health education training of malaria from dispatch agency, but less was from Entry-Exit Inspection and Quarantine (EIQ) and CDC. Health education training is so professional that different people should be take different training methods and strategies. The training effect would be threatened by the absence of professional organizations in health education training, 
which directly affect malaria knowledge of trainees. So professional health education training for overseas labors and cross-border travelers should be provided by public health authorities. In addition, Oversea Chinese had trained before going abroad and most parts of China had not reported local malaria cases since $2010[18,19]$. So, less education oversea labors were hard to realize the harmfulness of malaria and the way to prevent malaria. After living and working in malaria hyperendemic regions for a period of time, those who went abroad would take the initiative to acquire education of malaria prevention, then it is more conducive to conduct health education. Chinese flights to Africa are mainly concentrated in big cities such as Beijing, Shanghai, Guangzhou and so on. Therefore, cooperation and information exchange between various departments should be strengthened at the ports with a large number of inbound and outbound travelers to African countries, and the publicity of malaria prevention and control before going abroad and that in Africa should be carried out and strengthened.

In this study, through various forms of malaria knowledge training, the awareness rate of malaria knowledge among Chinese population in Sierra Leone increased from 44.4-87.63\%, which indicated significantly this health education interventions improved knowledge of malaria. This study investigated the mosquito breeding places of environment surrounding to learn about dwelling environment before the survey, so as to emphasize the different way to remove mosquito breeding places. Meanwhile, health education training from this study focused on the knowledge of mosquito control at different topography and the identification of malaria- mosquito specimens to strengthen mosquito control. And using life science video presentation and interactive mode of questions and answer, respondents are easier to understand the training contents when they have some experience on malaria endemic area. The Chinese in Sierra Leone have deepened their understanding of malaria prevention through local work and life, and also created many new problems and puzzles. Targeted solutions have been made to solve problems and significantly improved the effect of training. Chinese overseas workers in Africa, the places they worked generally lack medical resources with a weak public health foundation, and they are limited by language barrier and other factors, making it difficult to access local public health and medical services[20].There are great difference between different regions in Africa at malaria epidemics and the distribution of malaria-mosquito[21-23], hence, anti-malaria measures and health education should be carried out in the light of local conditions. In areas where transportation is difficult, domestic public health institutions may consider using the online "Internet + health service platform" to conduct distance health education and regular malaria prevention training for overseas workers, so as to improve the awareness and ability of self-protection to prevent malaria.

This study shows that the malaria infection rate of Chinese in Sierra Leone was $29.1 \%$, which was basically close to the local malaria infection rate of 32.0\% [1], and outdoor work was the key risk factors for infecting malaria. In the past five years, the infection rate of malaria in Sierra Leone has been around $35 \%$ [1] with a high prevalence of malaria, showing no trend of remission. Most of the study respondents were from the Freetown area of Sierra Leone, but the rate of malaria infection is likely to be higher in other rural areas of Sierra Leone where the natural environment is harsh and living conditions are difficult. Although in sierra leone in the vast majority of Chinese have used mosquito nets, installed screen door and window screens and used other anti-mosquito measures, but anopheles breeding ground is very 
ubiquitous with giving priority to with Gambia anopheles. More worryingly, the lack of mosquito control measures and the heavy burden of mosquito-borne disease control[24-29] aggravate a high incidence of malaria. The high temperature made it impossible for workers to wear long clothes and trousers outdoors all the time, and it is difficult to use mosquito repellents for long periods, thus outdoor workers in Sierra Leone are unable to avoid mosquito bites completely with a higher risk of malaria infection. Lack of medical resources and low access to medical services made it difficult for Chinese employees infected malaria to receive timely treatment, and infected cases easily became sources of infection and passed on to their peers. At present, it is generally accepted that the three major means of malaria prevention are mosquito control, physical and chemical measures to avoid bites and drug prevention[30].Therefore, for overseas Chinese, it is necessary to strengthen the economic input and implementation of malaria prevention and control, especially to take strict anti-mosquito measures in outdoor work.

In 2018-2019, among the imported malaria cases reported in China, labor workers and businessmen with mainly male young accounted for the first place, who spent more time in outdoor work with a higher risk of contracting malaria[14], and it was consistent with the characteristics of the malaria-infected population found in this study. In addition, the Chinese in Sierra Leone were mainly treated in local Chinese medical teams and private Chinese clinics for malaria. The data of these cases have not been reported or recorded in China's infectious disease reporting system, which is a blind spot in the management of imported cases. For example, the prevalence rate of malaria among Chinese population labor workers in Guinea was as high as $91 \%$, and most of them are infected overseas [29]. Malaria cases with foreign travel history found in China are recorded as imported cases[31], but most malaria cases infected overseas are not monitored. In order to reduce the incidence of imported malaria from the source, the measures of preventing malaria should move forward to overseas Chinese population, and health education and health input prevention should be strengthened among overseas Chinese.

\section{Conclusions}

In short, the Chinese in Sierra Leone were lack of knowledge of malaria with an inadequate training of malaria, and their awareness of malaria knowledge has been significantly improved through professional health education training. The rate of malaria infection among Chinese population in Sierra Leone with inadequate outdoor prevention was basically the same as that in the local area. Professional disease prevention and control institutions in China should strengthen malaria training for travelers to malariaendemic areas in Beijing and other ports with large outbound flows. The forms and contents of training should be enriched according to the characteristics of the population and the destination countries. Malaria training on the spot or live online training can be conducted. On the other hand, measures of prevention malaria should be strengthened. Outdoor workers should take measures such as wearing long clothes and long trousers, applying mosquito repellents, regularly cleaning the breeding places of mosquito, and carrying out physical and chemical elimination of mosquitoes and indoor spraying insecticide in places with infected cases. Through professional health education and prevention measures, that would improve the awareness of malaria knowledge, reduce the risk of malaria infection, 
reduce the risk of imported malaria from the source, and move forward the defensive barriers after the elimination of malaria in China.

\section{Declarations}

\section{Authors' contributions}

Hong Tu, Ning Zhao and Jun Feng conceived, designed and supervised the study. Hong Tu, Ning Zhao,Wei Luo, ZhaoJun Duan carried out the study, finalized and interpreted the analysis. Hong Tu, Ning Zhao and Jun Feng Wrote the drafts of the manuscript. Xiaohui Zou, Yingze Zhao Xiao Zheng,Yong Sun , Yang LIU, Jiangtao Ma , Jiayu Wan , Li-li Wang and Jianhai Yin assisted in data collection and analysis. Zhigui Xia, Zhaojun Duan Participated in the results interpretation and manuscripts revision. All authors read and approved the final manuscript.

\section{Acknowledgements}

This study was supported by grants from the Ministry of Science and Technology of China (the Key Techniques in Collaborative Prevention and Control of Major Infectious Diseases in the Belt and Road (No. 2018ZX10101002-004) and the National Science and Technology Major Program of China (No. 2018ZX10101002-002. The sponsor of the study had no role in the study design, data collection, analysis, and interpretation, preparation of the manuscript, or the decision to publish.

\section{Competing interests}

The authors declare that they have no competing interests

\section{References}

1. Organization WH: World malaria report 2019. In., vol. 2019; 2019.

2. Feng J, Zhang L, Huang F, Yin JH, Tu H, Xia ZG, Zhou SS, Xiao N, Zhou XN: Ready for malaria elimination: zero indigenous case reported in the People's Republic of China. Malar J 2018, 17(1):315.

3. Lai S, Sun J, Ruktanonchai NW, Zhou S, Yu J, Routledge I, Wang L, Zheng Y, Tatem AJ, Li Z: Changing epidemiology and challenges of malaria in China towards elimination. Malar J 2019, 18(1):107.

4. Lai S, Li Z, Wardrop NA, Sun J, Head MG, Huang Z, Zhou S, Yu J, Zhang Z, Zhou SS et al: Malaria in China, 2011-2015: an observational study. Bull World Health Organ 2017, 95(8):564-573.

5. Zhang X, Yao L, Sun J, Pan J, Chen H, Zhang L, Ruan W: Malaria in Southeastern China from 2012 to 2016: Analysis of Imported Cases. AM J TROP MED HYG 2018, 98(4):1107-1112.

6. Zhou S, Li Z, Cotter C, Zheng C, Zhang Q, Li H, Zhou S, Zhou X, Yu H, Yang W: Trends of imported malaria in China 2010-2014: analysis of surveillance data. Malar J 2016, 15:39. 
7. Yuan-Yuan C, Hua-Yun Z, Guo-Ding Z, Wei-Ming W, Jia-Jie J, Wen-Ji Q, Jia-Yan H, Jun C: [Challenges for maintaining achievements of malaria elimination in Jiangsu Province, China]. Zhongguo Xue Xi Chong Bing Fang Zhi Za Zhi 2018, 30(4):460-464.

8. Li Z, Zhang Q, Zheng C, Zhou S, Sun J, Zhang Z, Geng Q, Zhang H, Wang L, Lai S et al: Epidemiologic features of overseas imported malaria in the People's Republic of China. Malar J 2016, 15:141.

9. Ning Xiao QXJF: Approaching Malaria Elimination in China. In., vol. 2; 2020: 293.

10. Lai S, Wardrop NA, Huang Z, Bosco C, Sun J, Bird T, Wesolowski A, Zhou S, Zhang Q, Zheng C et al: Plasmodium falciparum malaria importation from Africa to China and its mortality: an analysis of driving factors. Sci Rep 2016, 6:39524.

11. Statistics NBO: China's labor cooperation with Africa at the end of the year. In., vol. 2019; 2019.

12. Statistics NBO: China's labor cooperation with Sierra Leone at the end of the year. In., vol. 2019; 2018.

13. Jun Feng HTLZ: Imported Malaria Cases - China, 2012-2018. In., vol. 2; 2020: 277.

14. Zhang M, Liu Z, He H, Luo L, Wang S, Bu H, Zhou X: Knowledge, attitudes, and practices on malaria prevention among Chinese international travelers. J TRAVEL MED 2011, 18(3):173-177.

15. Lei L, Richards JS, Li ZH, Gong YF, Zhang SZ, Xiao N: A framework for assessing local transmission risk of imported malaria cases. INFECT DIS POVERTY 2019, 8(1):43.

16. Li Z, Zhang Q, Zheng C, Zhou S, Sun J, Zhang Z, Geng Q, Zhang H, Wang L, Lai S et al: Epidemiologic features of overseas imported malaria in the People's Republic of China. Malar J 2016, 15:141.

17. Cao YY, Wang WM, Zhou HY, Zhu GD, Xu S, Gu YP, Zhang C, Liu YB, Cao J: [Cases diagnosis of imported malaria in Jiangsu province, 2014-2016]. Zhonghua Liu Xing Bing Xue Za Zhi 2018, 39(2):218-221.

18. Yuan-Yuan C, Hua-Yun Z, Guo-Ding Z, Wei-Ming W, Jia-Jie J, Wen-Ji Q, Jia-Yan H, Jun C: [Challenges for maintaining achievements of malaria elimination in Jiangsu Province, China]. Zhongguo Xue Xi Chong Bing Fang Zhi Za Zhi 2018, 30(4):460-464.

19. Yang WZ, Zhou XN: [New challenges of malaria elimination in China]. Zhonghua Yu Fang Yi Xue Za Zhi 2016, 50(4):289-291.

20. Yang WZ, Zhou XN: [New challenges of malaria elimination in China]. Zhonghua Yu Fang Yi Xue Za Zhi 2016, 50(4):289-291.

21. Ferede G, Tiruneh M, Abate E, Kassa WJ, Wondimeneh Y, Damtie D, Tessema B: Distribution and larval breeding habitats of Aedes mosquito species in residential areas of northwest Ethiopia. Epidemiol Health 2018, 40:e2018015.

22. Dida GO, Anyona DN, Abuom PO, Akoko D, Adoka SO, Matano AS, Owuor PO, Ouma C: Spatial distribution and habitat characterization of mosquito species during the dry season along the Mara River and its tributaries, in Kenya and Tanzania. INFECT DIS POVERTY 2018, 7(1):2.

23. Foley DH, Rueda LM, Wilkerson RC: Insight into global mosquito biogeography from country species records. J MED ENTOMOL 2007, 44(4):554-567. 
24. Dariano DF, Taitt CR, Jacobsen KH, Bangura U, Bockarie AS, Bockarie MJ, Lahai J, Lamin JM, Leski TA, Yasuda $C$ et al: Surveillance of Vector-Borne Infections (Chikungunya, Dengue, and Malaria) in Bo, Sierra Leone, 2012-2013. AM J TROP MED HYG 2017, 97(4):1151-1154.

25. Roth PJ, Grant DS, Ngegbai AS, Schieffelin J, McClelland RS, Jarrett OD: Factors associated with mortality in febrile patients in a government referral hospital in the Kenema district of Sierra Leone. AM J TROP MED HYG 2015, 92(1):172-177.

26. Ansumana R, Jacobsen KH, Leski TA, Covington AL, Bangura U, Hodges MH, Lin B, Bockarie AS, Lamin JM, Bockarie MJ et al: Reemergence of chikungunya virus in Bo, Sierra Leone. EMERG INFECT DIS 2013, 19(7):1108-1110.

27. de Araujo LJ, Mores CN, Bausch DG, Christofferson RC: Short Report: Serological Evidence of UnderReported Dengue Circulation in Sierra Leone. PLoS Neg/ Trop Dis 2016, 10(4):e4613.

28. Boisen ML, Schieffelin JS, Goba A, Oottamasathien D, Jones AB, Shaffer JG, Hastie KM, Hartnett JN, Momoh $\mathrm{M}$, Fullah $\mathrm{M}$ et al: Multiple circulating infections can mimic the early stages of viral hemorrhagic fevers and possible human exposure to filoviruses in Sierra Leone prior to the $\mathbf{2 0 1 4}$ outbreak. VIRAL IMMUNOL 2015, 28(1):19-31.

29. Schoepp RJ, Rossi CA, Khan SH, Goba A, Fair JN: Undiagnosed acute viral febrile illnesses, Sierra Leone. EMERG INFECT DIS 2014, 20(7):1176-1182.

30. Wangdi K, Furuya-Kanamori L, Clark J, Barendregt JJ, Gatton ML, Banwell C, Kelly GC, Doi S, Clements A: Comparative effectiveness of malaria prevention measures: a systematic review and network meta-analysis. Parasit Vectors 2018, 11(1):210.

31. Newby G, Bennett A, Larson E, Cotter C, Shretta R, Phillips AA, Feachem RG: The path to eradication: a progress report on the malaria-eliminating countries. LANCET 2016, 387(10029):1775-1784.

\section{Tables}


Table 1

Demographic profile, KAP of malaria and the rate of malaria infection within 1 year among Chinese population in Sierra Leone

\begin{tabular}{|c|c|c|c|c|}
\hline \multirow[t]{2}{*}{ Features } & \multirow[t]{2}{*}{ No.(\%) } & $\begin{array}{l}\text { The rate of } \\
\text { malaria }\end{array}$ & \multirow{2}{*}{$\begin{array}{l}\text { Awareness } \\
\text { rate before } \\
\text { training(\%)N } \\
=134\end{array}$} & \multirow{2}{*}{$\begin{array}{l}\text { Awareness } \\
\text { rate after } \\
\text { training(\%)N } \\
=131\end{array}$} \\
\hline & & $\begin{array}{l}\text { Infection\% } \\
(\mathrm{n} / \mathrm{N})\end{array}$ & & \\
\hline In total & 134(100.00) & $29.10(39 / 134)$ & $44.4 \pm 17.77$ & $\begin{array}{l}87.62 \pm \\
13.34\end{array}$ \\
\hline \multicolumn{5}{|l|}{ Gender } \\
\hline Male & $113(84.33)$ & $30.09(34 / 113)$ & $\begin{array}{l}42.43 \pm \\
17.32\end{array}$ & $\begin{array}{l}86.74 \pm \\
13.92\end{array}$ \\
\hline Female & $21(15.67)$ & $23.81(5 / 21)$ & $\begin{array}{l}55.03 \pm \\
16.75\end{array}$ & $92.5 \pm 8.12$ \\
\hline$\chi^{2} / T / F$ & & 0.338 & 3.077 & 1.794 \\
\hline$P$ & & 0.561 & 0.003 & 0.075 \\
\hline \multicolumn{5}{|l|}{ Age } \\
\hline$\nabla 45$ years & $82(61.19)$ & $35.37(29 / 82)$ & $\begin{array}{l}47.36 \pm \\
16.71\end{array}$ & $92.48 \pm 8.72$ \\
\hline$\geq 45$ years & $52(38.81)$ & 19.23(10/52) & $\begin{array}{l}39.74 \pm \\
18.55\end{array}$ & $\begin{array}{l}80.24 \pm \\
15.65\end{array}$ \\
\hline$\chi^{2} / T / F$ & & 4.015 & 2.462 & 5.139 \\
\hline$P$ & & 0.045 & 0.015 & 0.000 \\
\hline \multicolumn{5}{|l|}{ type of work } \\
\hline Outdoor work & $99(73.88)$ & $37.37(37 / 99)$ & $\begin{array}{l}43.66 \pm \\
16.23\end{array}$ & $\begin{array}{l}87.33 \pm \\
14.21\end{array}$ \\
\hline Indoor work & $35(26.12)$ & $5.71(2 / 35)$ & $\begin{array}{l}46.51 \pm \\
21.69\end{array}$ & $\begin{array}{l}88.41 \pm \\
10.73\end{array}$ \\
\hline$\chi^{2} / T / F$ & & 12.561 & 0.814 & 0.468 \\
\hline$P$ & & 0 & 0.417 & 0.682 \\
\hline \multicolumn{5}{|l|}{ Education background } \\
\hline Less than high school & $45(33.58)$ & $35.56(16 / 45)$ & $\begin{array}{l}31.98 \pm \\
14.71\end{array}$ & $\begin{array}{l}78.28 \pm \\
15.98\end{array}$ \\
\hline $\begin{array}{l}\text { Junior College and } \\
\text { Undergraduate }\end{array}$ & $56(41.79)$ & $33.93(19 / 56)$ & $\begin{array}{l}46.83 \pm \\
13.39\end{array}$ & $92.59 \pm 9.77$ \\
\hline
\end{tabular}




\begin{tabular}{|c|c|c|c|c|}
\hline Features & No.(\%) & $\begin{array}{l}\text { The rate of } \\
\text { malaria } \\
\text { Infection\% } \\
(\mathrm{n} / \mathrm{N})\end{array}$ & $\begin{array}{l}\text { Awareness } \\
\text { rate before } \\
\text { training(\%)N } \\
=134\end{array}$ & $\begin{array}{l}\text { Awareness } \\
\text { rate after } \\
\text { training(\%)N } \\
=131\end{array}$ \\
\hline Postgraduate and above & $33(24.63)$ & $12.12(4 / 33)$ & $\begin{array}{l}57.24 \pm \\
17.59\end{array}$ & $91.92 \pm 6.38$ \\
\hline$\chi^{2} / T / F$ & & 6.152 & 28.436 & 21.338 \\
\hline$P$ & & 0.046 & 0.000 & 0.000 \\
\hline \multicolumn{5}{|l|}{ Occupations } \\
\hline $\begin{array}{l}\text { Workers, business and } \\
\text { others }\end{array}$ & $105(78.36)$ & $35.24(37 / 105)$ & $\begin{array}{l}40.63 \pm \\
16.24\end{array}$ & $\begin{array}{l}86.33 \pm \\
14.51\end{array}$ \\
\hline $\begin{array}{l}\text { Teachers, medical staff } \\
\text { and researchers }\end{array}$ & $29(21.64)$ & $6.9(2 / 29)$ & $\begin{array}{l}58.05 \pm \\
16.57\end{array}$ & $92.15 \pm 6.21$ \\
\hline$\chi^{2} / T / F$ & & 8.846 & 5.030 & 3.156 \\
\hline$P$ & & 0.003 & 0.000 & 0.038 \\
\hline \multicolumn{5}{|l|}{ Type of institution } \\
\hline $\begin{array}{l}\text { Government departments } \\
\text { and institutions }\end{array}$ & $31(23.13)$ & $3.22(1 / 31)$ & $\begin{array}{l}53.41 \pm \\
20.32\end{array}$ & $\begin{array}{l}86.78 \pm \\
14.45\end{array}$ \\
\hline Company and private & $103(76.87)$ & $36.89(38 / 103)$ & $\begin{array}{l}41.69 \pm \\
16.07\end{array}$ & $90.32 \pm 8.48$ \\
\hline$\chi^{2} / T / F$ & & 13.090 & 3.337 & 1.688 \\
\hline$P$ & & 0.000 & 0.001 & 0.197 \\
\hline \multicolumn{5}{|l|}{$\begin{array}{l}\text { Whether to receive malaria } \\
\text { control training before } \\
\text { going abroad }\end{array}$} \\
\hline Yes & $66(49.25)$ & $22.79(15 / 66)$ & $\begin{array}{l}47.98 \pm \\
17.96\end{array}$ & $\begin{array}{l}88.64 \pm \\
12.74\end{array}$ \\
\hline No & $68(50.75)$ & $29.41(20 / 68)$ & $\begin{array}{l}40.93 \pm \\
17.01\end{array}$ & $\begin{array}{l}86.55 \pm \\
13.96\end{array}$ \\
\hline$\chi^{2} / T / F$ & & 0.006 & 2.333 & 0.898 \\
\hline$P$ & & 0.937 & 0.021 & 0.371 \\
\hline \multicolumn{5}{|l|}{$\begin{array}{l}\text { Whether to use mosquito } \\
\text { nets every day }\end{array}$} \\
\hline Yes & $113(84.33)$ & $29.52(33 / 113)$ & $\begin{array}{l}45.08 \pm \\
17.52\end{array}$ & $\begin{array}{l}87.30 \pm \\
15.26\end{array}$ \\
\hline
\end{tabular}




\begin{tabular}{|c|c|c|c|c|}
\hline Features & No.(\%) & $\begin{array}{l}\text { The rate of } \\
\text { malaria } \\
\text { Infection\% } \\
(\mathrm{n} / \mathrm{N})\end{array}$ & $\begin{array}{l}\text { Awareness } \\
\text { rate before } \\
\text { training(\%)N } \\
=134\end{array}$ & $\begin{array}{l}\text { Awareness } \\
\text { rate after } \\
\text { training(\%)N } \\
=131\end{array}$ \\
\hline No & $21(15.67)$ & $27.58(6 / 21)$ & $\begin{array}{l}41.95 \pm \\
18.76\end{array}$ & $\begin{array}{l}87.70 \pm \\
12.85\end{array}$ \\
\hline$\chi^{2} / T / F$ & & 0.041 & 0.837 & 0.140 \\
\hline$P$ & & 0.839 & 0.404 & 0.889 \\
\hline \multicolumn{5}{|c|}{$\begin{array}{l}\text { Have you used mosquito } \\
\text { pesticides }\end{array}$} \\
\hline Yes & $100(74.63)$ & $31.00(31 / 100)$ & $\begin{array}{l}50.33 \pm \\
18.19\end{array}$ & $\begin{array}{l}86.51 \pm \\
14.38\end{array}$ \\
\hline No & $34(25.37)$ & $23.53(8 / 34)$ & $\begin{array}{l}42.39 \pm \\
17.26\end{array}$ & $90.91 \pm 8.98$ \\
\hline$\chi^{2} / T / F$ & & 0.686 & 2.285 & 1.651 \\
\hline$P$ & & 0.407 & 0.024 & 0.101 \\
\hline \multicolumn{5}{|c|}{$\begin{array}{l}\text { Have you used repellent } \\
\text { outside your home }\end{array}$} \\
\hline Yes & $99(73.88)$ & $30.30(30 / 99)$ & $\begin{array}{l}46.24 \pm \\
17.18\end{array}$ & $\begin{array}{l}88.77 \pm \\
12.37\end{array}$ \\
\hline No & $35(26.12)$ & 25.71(9/35) & $\begin{array}{l}39.71 \pm \\
18.66\end{array}$ & $\begin{array}{l}85.18 \pm \\
14.87\end{array}$ \\
\hline$\chi^{2} / T / F$ & & 0.594 & 1.797 & 1.366 \\
\hline$P$ & & 0.743 & 0.078 & 0.174 \\
\hline \multicolumn{5}{|c|}{$\begin{array}{l}\text { Whether to install screen } \\
\text { door and screen window in } \\
\text { your house }\end{array}$} \\
\hline Yes & 121(90.30) & $27.27(33 / 121)$ & $\begin{array}{l}44.95 \pm \\
17.42\end{array}$ & $\begin{array}{l}87.72 \pm \\
13.61\end{array}$ \\
\hline No & 13(9.70) & $46.15(6 / 13)$ & $\begin{array}{l}39.32 \pm \\
20.84\end{array}$ & $\begin{array}{l}86.57 \pm \\
10.71\end{array}$ \\
\hline$\chi^{2} / T / F$ & & 2.028 & 1.087 & 0.283 \\
\hline$P$ & & 0.154 & 0.279 & 0.778 \\
\hline
\end{tabular}


Table 2

Factors associated with awareness rate in malaria prevention and control among Chinese population in Sierra Leone

\begin{tabular}{|lll|}
\hline Factor & OR $(95 \% \mathrm{Cl})$ & P value \\
\hline Age $\geq 45$ years & $2.6(1.2,5.7)$ & 0.019 \\
\hline Gender - Male & $3.2(1.1,9.4)$ & 0.030 \\
\hline Education - Junior or lower & $0.4(0.1,2.3)$ & 0.312 \\
\hline Education - undergraduate or higher & $0.8(0.2,3.6)$ & 0.720 \\
\hline Occupation-worker and business & $0.6(0.1,6.3)$ & 0.662 \\
\hline Sending organization -Company or private - & $0.1(0,1.1)$ & 0.064 \\
\hline
\end{tabular}

Table 3

Factors associated with infected rate in malaria prevention and control among Chinese population in Sierra Leone

\begin{tabular}{|lll|}
\hline Factor & OR $(95 \% \mathrm{Cl})$ & P value \\
\hline Age $\geq 45$ years & $3.0(1.0,8.8)$ & 0.045 \\
\hline Work type-Outdoor work & $6.5(1.3,31.7)$ & 0.021 \\
\hline Education - Junior or lower & $1.7(0.6,4.9)$ & 0.325 \\
\hline Education - undergraduate or higher & $2.2(0.4,12.7)$ & 0.367 \\
\hline Occupation-worker and business & $0.6(0.1,6.3)$ & 0.671 \\
\hline Sending organization -Company or private - & $0.1(0,1.2)$ & 0.065 \\
\hline
\end{tabular}




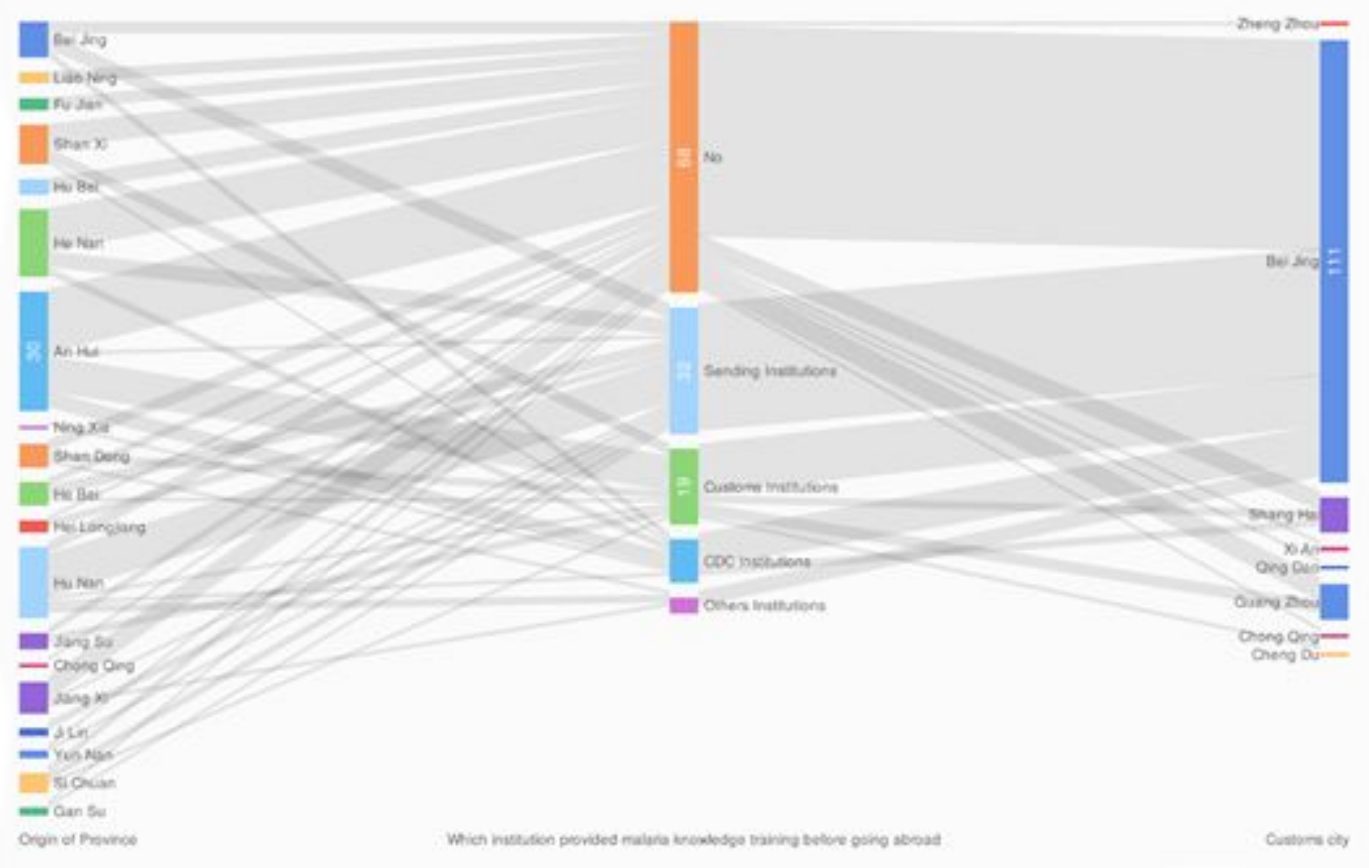

Figure 1

The Sankey diagram of health education training of malaria and outbound migration among Chinese population in Sierra Leone 